\title{
Production of a Biofuel that Keeps the Glycerol as a Monoglyceride by Using Supported KF as Heterogeneous Catalyst ${ }^{\dagger}$
}

Juan Calero ${ }^{1}{ }^{*}$, Gema Cumplido ${ }^{1}$, Diego Luna ${ }^{1}$, Enrique D. Sancho ${ }^{2}$, Carlos Luna ${ }^{1}$, Alejandro Posadillo ${ }^{3}$, Felipa M. Bautista ${ }^{1}$, Antonio A. Romero ${ }^{1}$ and Cristóbal Verdugo-Escamilla ${ }^{4}$

1 Department of Organic Chemistry, University of Córdoba, Campus de Rabanales, Ed. Marie Curie, E-14014 Córdoba, Spain; E-Mails: curug82@gmail.com (G.C.); qo1lumad@uco.es (D.L.); qo2luduc@uco.es (C.L.); qo1baruf@uco.es (F.M.B.); qo1rorea@uco.es (A.A.R.)

2 Department of Microbiology, University of Córdoba, Campus de Rabanales, Ed. Severo Ochoa, E-14014 Córdoba, Spain; E-Mail: edsancho@uco.es

3 Seneca Green Catalyst S.L., Campus de Rabanales, E-14014 Córdoba, Spain; E-Mail: seneca@uco.es

4 Laboratorio de Estudios Cristalográficos, Instituto Andaluz de Ciencias de la Tierra (IACT), Spanish National Research Council (CSIC)-Universidad de Granada, Av. de las Palmeras 4, E-18100 Armilla, Granada, Spain; E-Mail: cristobal.verdugo@csic.es

$\dagger$ This paper was previously presented at the 1st International e-Conference on Energies, 2013, c002; doi:10.3390/ece-1-c002, available online: http://www.sciforum.net/conference/ece-1/paper/2328.

* Author to whom correspondence should be addressed; E-Mail: p72camaj@uco.es; Tel.: +34-957-212-065; Fax: +34-957-212-066.

Received: 22 April 2014; in revised form: 4 June 2014 / Accepted: 10 June 2014 / Published: 18 June 2014

Abstract: This study describes the results obtained in the synthesis of a biofuel that avoids the production of glycerol by applying supported KF as alkaline heterogeneous catalyst, to generate two moles of fatty acid methyl esters and one mole of monoglyceride from one mol of triglyceride. In this respect, the selective transesterification process of sunflower oil with methanol was carried out with $\mathrm{KF}$ (10 $\mathrm{wt} \%)$ supported on three different solids, $\mathrm{Al}_{2} \mathrm{O}_{3}, \mathrm{ZnO}$ and $\mathrm{MgO}$. The standard experimental conditions employed in the heterogeneous selective methanolysis reaction were: $12 \mathrm{~mL}$ of sunflower oil, $2.7 \mathrm{~mL}$ of methanol, $0.8 \mathrm{~g}$ of catalyst, at $65{ }^{\circ} \mathrm{C}$ temperature and one hour of reaction time. In all cases $100 \%$ conversion was obtained, with high selectivity values, greater than $90 \%$, and quite suitable viscosity 
values, 4.5-8.5 cSt. In this way, the best catalytic behavior in the first use was obtained by using $\mathrm{Al}_{2} \mathrm{O}_{3}$ as support. However, although in the five consecutive reuses all catalysts exhibited a continuous decrease in their catalytic activities; the lower one was for KF catalyst using $\mathrm{MgO}$ as support. In summary, these three KF supported catalysts are very suitable to obtain a new biofuel, similar to conventional biodiesel, applicable to diesel engines.

Keywords: biodiesel; sunflower oil; methanolysis; supported KF; monoacylglycerol

\section{Introduction}

Oil is currently indisputably the main source of energy, with a demand of about 12 million tons per day, and a projected increase to 16 million tons per day by 2030 [1]. It is estimated that within 50 years, some oil reserves in some countries will be depleted, and many of the remaining sites (located at great depth and/or in oceans) will be inaccessible, which will inevitably cause rising oil prices as well as increasing anthropogenic emissions of greenhouse gases (GHG) causing the global warming effect. Thus, the research efforts on different renewable fuels have grown in the last years [2]. However, is widely accepted that this target will not be easy to implement, and it will require a major coordinated effort by many groups - political forces, scientific organizations, economic and social actors, and of course the citizens - to access and develop new economic and social scenarios where the energy and commodities will not be, as currently happens, completely dependent on fossil oil and consequently GHG producers [3].

The term biodiesel is currently reserved for those biofuels made of a mixture of monoalkyl esters of long chain fatty acids, derived from renewable lipids such as vegetable oils or animal fats, that can be used in the current combustion engines without any modification, as they have physicochemical properties similar to conventional fuels. Besides, they offer additional advantages, like being renewable, biodegradable and nontoxic compounds, that are essentially free of sulfur and aromatics so that it represents an added value due to their environmental safety [4,5].

The benefits of biofuels over traditional fuels include also greater energy security, reduced environmental impact, foreign exchange savings, and positive socioeconomic issues related to the rural sector. The use of waste oils and fats in biodiesel production also reduces many environmental complications and could be friendly energy drivers for all countries [6]. Thus, in recent years biodiesel production has become a very important potential alternative to partially fulfill the expected future energy demands in the transport sector [7,8]. In this connection, the most usual technology to process vegetable oils or animal fats is based on the conversion of the triglycerides (TG) to fatty acids methyl esters (FAME) by a transesterification reaction with methanol. However, there are also several alternative routes to use vegetable oils or animal fats like a biofuel, including direct use of vegetable oil, microemulsions and emulsifications [9].

Regardless of the procedure used to obtain the so-called conventional biodiesel (homogeneous or heterogeneous, acid or basic catalysts, lipases, supercritical conditions, etc.), in all cases the glycerol is formed as a by-product, representing a notable performance loss in the process, given that the market is already virtually flooded with the produced glycerine, obtained precisely as a by-product in the 
current manufacture of biodiesel [10,11]. Thus, this current method supposes a decreased yield of the process, always higher than nominal $12 \mathrm{wt} \%$, due to the glycerol obtained as a reaction product, which in very small amount is also incorporated to the biodiesel (FAME, Fatty Acid Methyl Ester) phase. In this respect, the cleaning of glycerol is necessary, because of its ability to react with oxygen inside the engine at high temperature, where it could produce dehydration forming acrolein, that can be polymerised causing several problems, including coking of fuel. This coking can also generate deposits of carbonaceous compounds on the injector nozzles, pistons and valves in standard engines, thus reducing their efficiency and even their service life $[1,8]$.

To avoid the problems associated with the generation of glycerol in the conventional process, a series of alternative methods are considered to get the highest atom efficiency by avoiding the production of glycerin. Thus, a target of great interest currently is the production, in only one reaction, of new biofuels that integrate the glycerol as a derivative product, miscible with the fatty acid methyl or ethyl esters (FAME or FAEE) obtained in the same transesterification process. Basically, this is possible by using some alternative esters, instead of the alcohol usually employed in the conventional process. Thus, if some glycerol derivative compound is obtained at the same time that FAME (or FAEE) in an interesterification process, a new biofuel is obtained in only one reaction avoiding the presence of glycerol, that is, instead of glycerol its corresponding ester is obtained, together to the FAME mixture. These new biofuels not only prevent the generation of waste glycerol, but also increase the yields of the process, always higher than nominal $12 \mathrm{wt} \%$, by incorporating some glycerol derivatives into the reaction products. In this way, the highest atom efficiency, practically $100 \mathrm{wt} \%$, is obtained. Novel methodologies to prepare esters from lipids using different acyl acceptors which directly afford alternative co-products are currently under development [12].

The interesterification processes can be performed with the same catalysts applied in the standard transesterification processes (homogeneous or heterogeneous, acid or basic catalysts, lipases, supercritical conditions, etc.), although at present most of these processes, when applied to the production of biofuels, are carried out using different lipases [12], where instead of using methanol, the lipase-catalyzed synthesis of fatty acid alkyl esters can also be performed using alternative alcohol donors such as methyl or ethyl (alkyl) acetate and dimethyl or diethyl carbonate. These mixtures including glycerol derivative molecules have relevant physical properties to be employed as novel biofuels. The atom efficiency is also improved as all the atoms involved in the reaction become part of the final mixture. Even the reactants used remain together to the obtained reaction products to be directly used as biofuels [12-18]. Thus, the transesterification reaction of triglycerides with dimethyl carbonate (DMC) $[13,14]$ generates a mixture of FAME and glycerol carbonate (GC), which is soluble in FAME and has physical properties suitable for use as fuel, so it has been introduced as a new biofuel called DMC-BIOD [15]. Similarly, the transesterification of methyl acetate with some vegetable oils generates Gliperol ${ }^{\circledR}$ (Warsaw, Poland), a new patented biofuel [16-18] constituted by three molecules of FAME and one molecule of triacetin or glycerol triacetate.

In recent studies an alternative methodology is implemented that avoids the generation of glycerol by developing a partial enzymatic ethanolysis of the triglyceride molecules, that generates two molecules of fatty acid ethyl esters (FAEE) and a molecule of monoacylglycerol (MG). This enzymatic method using pig pancreatic lipase (PPL) to cause the enantioselective ethanolysis of sunflower oil has shown promising results [19-24] in the preparation of a new biofuel patented by 
University of Cordoba, named Ecodiesel-100 [22]. This method takes advantage of the 1.3-selective nature of many lipases, which allows stopping the process in the second step of the alcoholysis reaction to obtain a mixture of two moles of FAEE and one MG. In this respect it is interesting to point out in this respect that according to recent studies the presence of MG enhances the lubricating properties of the biofuel $[25,26]$. So far this process is being developed not only with PPL but also with some microbial lipases, both in free and immobilized forms [19-24].

The current existing limitations to the use of lipases are mainly associated with their high costs, so that in order to achieve an increase in viability and competitiveness respect to the enzymatic process, the present study aims to achieve the partial transesterification reaction, through the kinetic control of the chemical reaction, to obtain the same results previously described in stereoselective enzymatic processes. Thus, now is intended to obtain the same new biodiesel that contains monoacylglycerol, by using KF as alkaline heterogeneous catalyst, as an alternative to the more expensive lipases (Figure 1).

Figure 1. Representative scheme of the production of Ecodiesel, a biofuel, by partial methanolysis of sunflower oil.

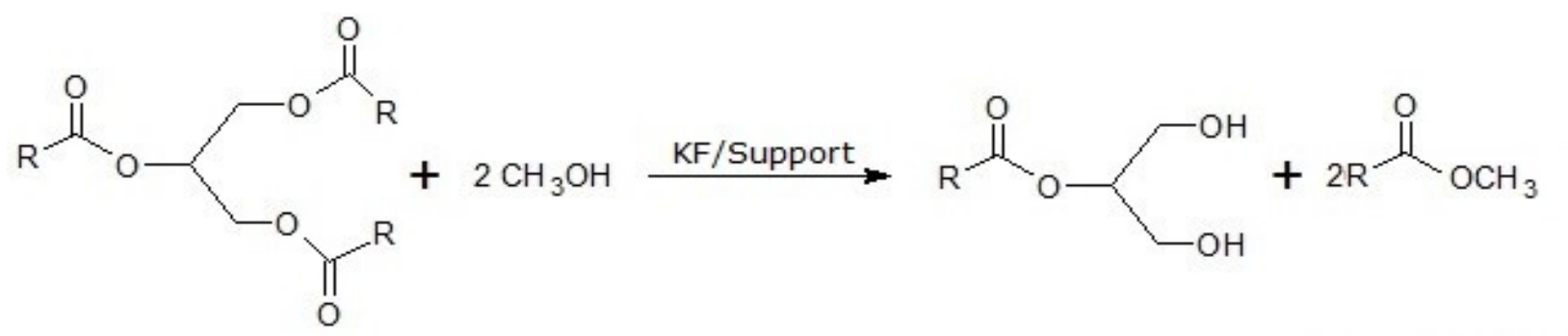

Triglyceride

Methanol

Monoglyceride

Fatty Acid Methyl Ester (FAME)

In this respect, some promising results have been previously obtained by using $\mathrm{CaO}$ as an alkaline heterogeneous catalyst [27]. In the present research, a series of supported KF catalysts, previously applied as basic catalysts in some organic synthetic processes [28], are investigated in the methanolysis reaction of sunflower oil to obtain the desired selective transesterification, through the kinetic control of the consecutive chemical process, to get the same biodiesel without glycerol generation, as an alternative to the more expensive lipases.

Taking into account that the transesterification reaction is a sequential process consisting in three successive methanolysis steps, where a molecule of TG (triglyceride) and three molecules of methanol lead to a molecule of glycerol and three of FAME, it is conceivable that some kinetic parameters like amount of catalyst, molar oil/methanol ratio, reaction temperature and the reaction time could be critical parameters to control in order to develop a selective process with only two successive methanolysis steps to keep the glycerol as a monoglyceride (Figure 1).

On the other hand, heterogeneous catalysts, unlike to homogeneous ones, are environmentally benign and could operate in continuous processes. Moreover, they can be reused and regenerated. Among them, supported-KF catalysts seems to have a promising place according to the increasing number of research works devoted to its capability to catalyze the triglyceride methanolysis reaction [29-36]. In contrast, no reports have been found regarding the catalytic behaviour of supported $\mathrm{CsF}, \mathrm{NaF}$ or LiF in transterification reactions of oils or fats to obtain biodiesel [37]. 
However, despite the success obtained with supported KF catalysts [29-37], one always gets a marked decrease in the catalytic activity, as compared to homogeneous catalysis, which requires operating at higher temperatures and pressures, with higher oil/methanol proportions, which so far has discouraged their implementation on an industrial scale for the conventional biodiesel production.

Nevertheless, this weaker basic character of supported KF catalysts could be an important advantage to achieve a selective methanolysis, where the process is stopped in the second step (like in Figure 1), after optimizing the experimental conditions (catalyst weight, oil/methanol relative concentration, temperature, reaction time, etc.) to achieve the kinetic control of the selective methanolysis process. In this way, the use of heterogeneous low cost catalysis to produce a biofuel without glycerol generation, could solve many of the problems of conventional homogeneous catalysts $(\mathrm{NaOH}$ or $\mathrm{KOH})$, because the yields of the process are increased (10-12 wt \%), the neutralization step of the reaction products is avoided, as well as the cleaning process after the synthesis of biodiesel and the waste management of glycerol generated.

\section{Results and Discussion}

\subsection{Influence of the Inorganic Solid Used as KF Support on Process Performance}

Among the different inorganic solids described in the literature as supports of KF to obtain heterogeneous basic catalysts useful in the production of conventional biodiesel [29-37], in the current study $\mathrm{Al}_{2} \mathrm{O}_{3}, \mathrm{ZnO}$ and $\mathrm{MgO}$ have been evaluated as supports of $\mathrm{KF}$ at $10 \mathrm{wt} \%$. These were obtained following the experimental methodology previously described [28]. To determine the comparative behaviour of the different supported KF systems, Table 1 collects the results obtained when operating under the standard conditions previously determined with $\mathrm{CaO}$ heterogeneous catalysts [27]. Thus, reactions were carried out with $0.8 \mathrm{~g}$ of $10 \mathrm{wt} \%$ supported $\mathrm{KF}$ on the three inorganic solids, $\mathrm{Al}_{2} \mathrm{O}_{3}, \mathrm{ZnO}$ and $\mathrm{MgO}$, at $65^{\circ} \mathrm{C}$ reaction temperature with $12 \mathrm{~mL}$ of sunflower oil (32 cSt, kinematic viscosity) and $2.43 \mathrm{~mL}$ of methanol.

Table 1. Reactions performed under standard conditions, using $12 \mathrm{~mL}$ of sunflower oil (viscosity $32.0 \mathrm{cSt}$ ) $2.43 \mathrm{~mL}$ of methanol, reaction time $60 \mathrm{~min}$, temperature $65{ }^{\circ} \mathrm{C}$ and $0.8 \mathrm{~g}$ of $\mathrm{KF} 10 \mathrm{wt} \%$ supported on various inorganic solids weight $\mathrm{Al}_{2} \mathrm{O}_{3}, \mathrm{ZnO}$ and $\mathrm{MgO}$.

\begin{tabular}{cccc}
\hline Support & Viscosity (cSt) & Conversion (\%) & Selectivity (\%) \\
\hline $\mathrm{Al}_{2} \mathrm{O}_{3}$ & 4.62 & 100 & 94.95 \\
$\mathrm{ZnO}$ & 8.40 & 100 & 83.54 \\
$\mathrm{MgO}$ & 5.88 & 100 & 92.40 \\
\hline
\end{tabular}

According to the results, with all the three KF supported catalysts studied, under the indicated experimental conditions, similar results to those achieved in the enzymatic processes were obtained [19-24], where instead of glycerol monoacylglycerols that are soluble in the FAME mix are obtained. The experimental conditions currently applied were clearly milder than those required for the production of conventional biodiesel with supported KF catalysts [29-37]. These results are also similar to those obtained with $\mathrm{CaO}[27,38]$ in regard to the values of conversion and selectivity parameters; however are better respect to the kinematic viscosity values obtained. 
Taking into account the best results obtained with $\mathrm{Al}_{2} \mathrm{O}_{3}$ as support of $\mathrm{KF}$, this basic heterogeneous catalyst was chosen to obtain an improved set of reaction parameters like the amount of catalyst, molar oil/methanol ratio and temperature, to optimize as much as possible the experimental conditions to improve the selective methanolysis process of sunflower oil. Thus, although similar values of kinematic viscosity are obtained to those of conventional biodiesel derived from sunflower oil, that presents values in the range 4-6 cSt, it seems necessary to better optimize the experimental operating conditions, since the proposed objective is to determine the experimental conditions that allow to obtain a viscosity as low as possible, without producing glycerol, under milder and greener operation conditions.

\subsection{Influence of Catalyst $\mathrm{KF} / \mathrm{Al}_{2} \mathrm{O}_{3}$ Weight on Process Performance}

Under the determined operating conditions (temperature, oil/methanol ratio and reaction time) in a heterogeneously catalyzed process, the amount of catalyst used determines whether the operating conditions are kinetically controlled or not. In such a case, the catalytic activity is directly proportional to the weight of catalyst used. Outside this region, in which the weight of the catalyst does not affect the performance of the process, the results are not related to the catalytic properties of the solid studied, indicating that the kinetic control of the consecutive methanolysis reaction, passes from the catalyst to the reactants, so that the higher amounts of catalyst will remain practically inactive (the active sites of catalyst surface are starved of reactants). Thus, first of all it is necessary to confirm that the standard conditions previously indicated in Table 1, allows one to operate under kinetic control of the methanolysis process studied.

In this respect, to evaluate the influence of the weight of the catalyst, different amounts of $\mathrm{KF} / \mathrm{Al}_{2} \mathrm{O}_{3}$ catalysts (from 0.2 to $1 \mathrm{~g}$ ) have been used under the same standard experimental conditions indicated in Table $1,\left(65{ }^{\circ} \mathrm{C}, 12 \mathrm{~mL}\right.$ oil, $2.43 \mathrm{~mL}$ methanol and $60 \mathrm{~min}$ reaction times). Results obtained are collected in Figure 2. These results show that, under the standard experimental conditions, Conversion and Selectivity increasingly grow to practically reach a maximum with $\mathrm{KF} / \mathrm{Al}_{2} \mathrm{O}_{3}$ amounts higher than $0.8 \mathrm{~g}$ ( $7 \mathrm{wt} \%$ respect to oil) where the kinematic viscosity values are around $4.5 \mathrm{cSt}$. The kinematic viscosity values exhibit more clearly the typical behavior of a heterogeneous process developed under kinetic control due to the straight decrease of viscosity values obtained on increasing the catalyst weight.

Furthermore, the fact that in no case the slightest amount of glycerol was obtained, according to the GC analysis of the reaction products, highlights the undoubtedly selective character of the consecutive methanolysis process. This can be explained as a consequence of the fact that the selective nature of the process is based on the strength of the active basic sites, more than on the number of these active sites. Accordingly it can be concluded that the basic sites of the KF catalysts have enough strength to carry out the methanolysis of the primary hydroxylic bonds of triglycerides, in the 1 and 3 positions of glycerol, but these basic sites on the KF catalysts are not enough strong to be able to promote the transesterification of the less active secondary alcohol, in position 2 of glycerol. 
Figure 2. (a) Viscosity values and (b) Conversion and Selectivity values, obtained in the heterogeneous selective methanolysis of sunflower oil under standard conditions, with different amounts of $\mathrm{KF} / \mathrm{Al}_{2} \mathrm{O}_{3}$, reaction time $60 \mathrm{~min}$, reaction temperature $65{ }^{\circ} \mathrm{C}, 12 \mathrm{~mL}$ of oil and $2.43 \mathrm{~mL}$ of methanol.

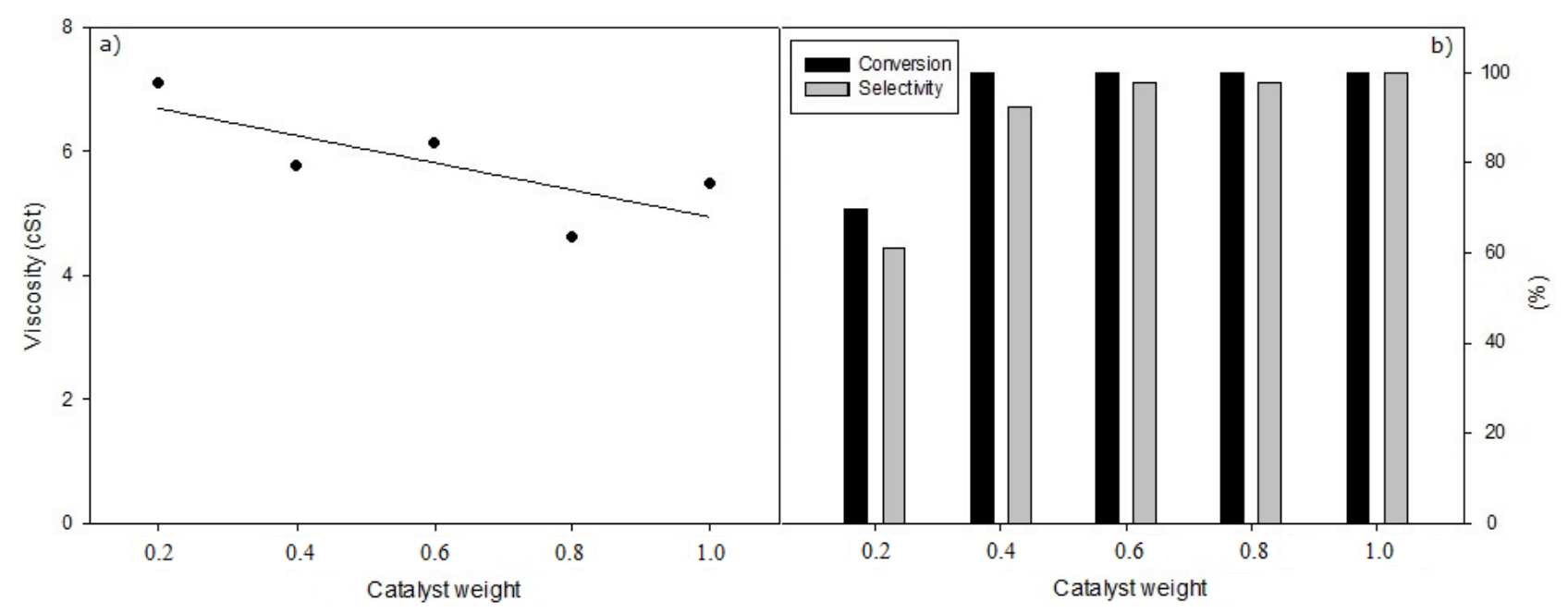

The use of higher catalyst amounts will not promote increasing catalytic activity because under these conditions kinetic control of the reaction does not operate. This indicates that the best experimental conditions are obtained by using $8 \mathrm{wt} \%$ of heterogeneous $\mathrm{KF}$ catalyst, respect to the amount of oil used.

\subsection{Influence of Molar Oil/Methanol Ratio on Process Performance}

The influence of the molar (oil/methanol) ratio on the catalytic performance of the methanolysis process was determined operating under the standard experimental conditions previously considered in Table 1 (reaction time $60 \mathrm{~min}, 65{ }^{\circ} \mathrm{C}, 0.8 \mathrm{~g} \mathrm{KF} / \mathrm{Al}_{2} \mathrm{O}_{3}$ and $12 \mathrm{~mL}$ oil) using different amounts of methanol from 1.2 to $2.8(1 / 3$ to $1 / 7)$. The results shown in Figure 3 indicate that despite the continuous decrease in kinematic viscosity values, Conversion, and mainly Selectivity, reach a maximum at a molar oil/methanol ratio of $1 / 5$.

According to the mass action law governing the chemical equilibrium in reversible processes, the Conversion and Selectivity could be improved by introducing excess quantities of methanol to shift the equilibrium and get a higher amount of FAME. The experimental results, collected in Figure 3, accordingly indicate that the biodiesel yield (Conversion and Selectivity) grew with increasing molar relation oil/alcohol until it reached the maximum value (1/5) but, when this increase continues, the methanolysis reaction yield is then lowered. Thus, the molar ratio of methanol to oil has a significant impact on the viscosity of the obtained biodiesel, where the lowest viscosity value is associated to higher Conversion and Selectivity values, $100 \%$ and $98.8 \%$, respectively. 
Figure 3. (a) Viscosity values and (b) Conversion and Selectivity values, obtained in the heterogeneous selective methanolysis of sunflower oil under standard conditions, with different molar oil/methanol ratios, reaction time $60 \mathrm{~min}$, reaction temperature $65{ }^{\circ} \mathrm{C}$, $12 \mathrm{~mL}$ oil and $0.8 \mathrm{~g}$ of $\mathrm{KF} / \mathrm{Al}_{2} \mathrm{O}_{3}$.

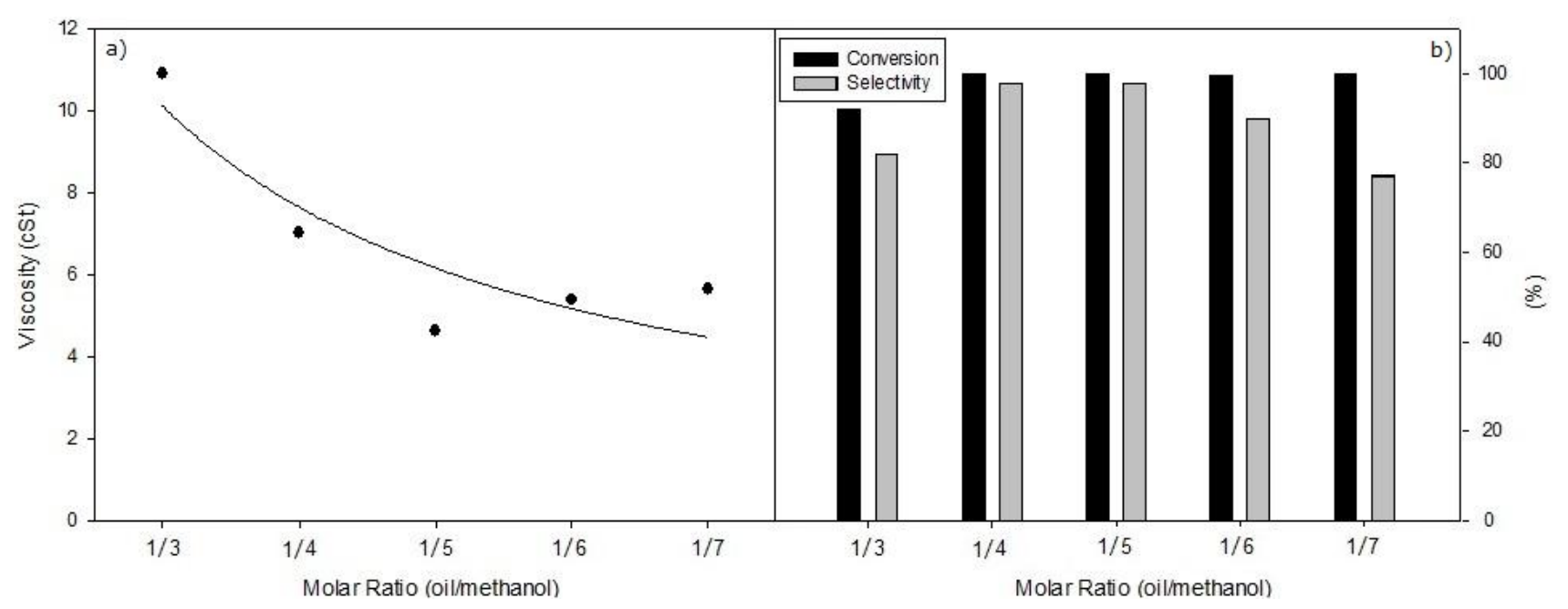

\subsection{Influence of Temperature on Process Performance}

The optimized conditions (weight of catalyst, reaction time and molar oil/alcohol ratio) have been established according to an elevated temperature, $65^{\circ} \mathrm{C}$. However, the evaluation of the influence of reaction temperature on reaction performance may provide information of interest in relation to the catalysed reaction mechanism of the sunflower oil methanolysis process. Thus, under the experimental conditions of Table 1 (time reaction $60 \mathrm{~min}, 0.8 \mathrm{~g} \mathrm{KF} / \mathrm{Al}_{2} \mathrm{O}_{3}, 12 \mathrm{~mL}$ oil and $2.43 \mathrm{~mL}$ methanol) several reactions were carried out at different temperatures in the 45 to $65{ }^{\circ} \mathrm{C}$ range. Results shown in Figure 4 indicate that Conversion and Selectivity reach the highest value, $100 \%$ and $99.9 \%$ respectively, at $50{ }^{\circ} \mathrm{C}$, however viscosity values exhibit a continuous decrease with increasing temperature.

Recalling that the Selectivity is connected to those methanolysis products with similar RT (retention time) values to those hydrocarbons that comprise conventional fossil diesel, and in this interval not only the different FAMEs are present, but also the corresponding MGs. Besides, a 99\% Selectivity with Conversion of $100 \%$ would indicate the presence of at least $1 \%$ of DG (diglyceride), so that the viscosity obtained is somewhat higher that corresponding to pure the FAME constituting conventional biodiesel. That is, it is perfectly possible for two reaction samples with similar Conversion and Selectivity values to differ in viscosity values. Thus, it is concluded the greater relevance of the viscosity with respect to the Conversion and Selectivity data, with respect to the information obtained on the consecutive reaction progress of sunflower oil methanolysis.

In this respect, the viscosity appears as the most sensitive parameter to the progress of the reaction where the Arrhenius equation that fit Equations (1) and (2) it can be applied as can be seen in Figure 5, where the kinematic viscosity is a parameter directly related to the reaction rate constants:

$$
\begin{gathered}
k=A \cdot \exp (-E a / R T) \\
\operatorname{Ln} k=\operatorname{Ln} A-(E a / R T)
\end{gathered}
$$


Figure 4. (a) Viscosity values and (b) Conversion and Selectivity values, obtained in the heterogeneous selective methanolysis of sunflower oil carried out under standard conditions, reaction time $60 \mathrm{~min}, 0.8 \mathrm{~g}$ of $\mathrm{KF} / \mathrm{Al}_{2} \mathrm{O}_{3}$ catalyst, $12 \mathrm{~mL}$ of oil and $2.43 \mathrm{~mL}$ of methanol, under different reaction temperatures in the interval $45-65^{\circ} \mathrm{C}$.

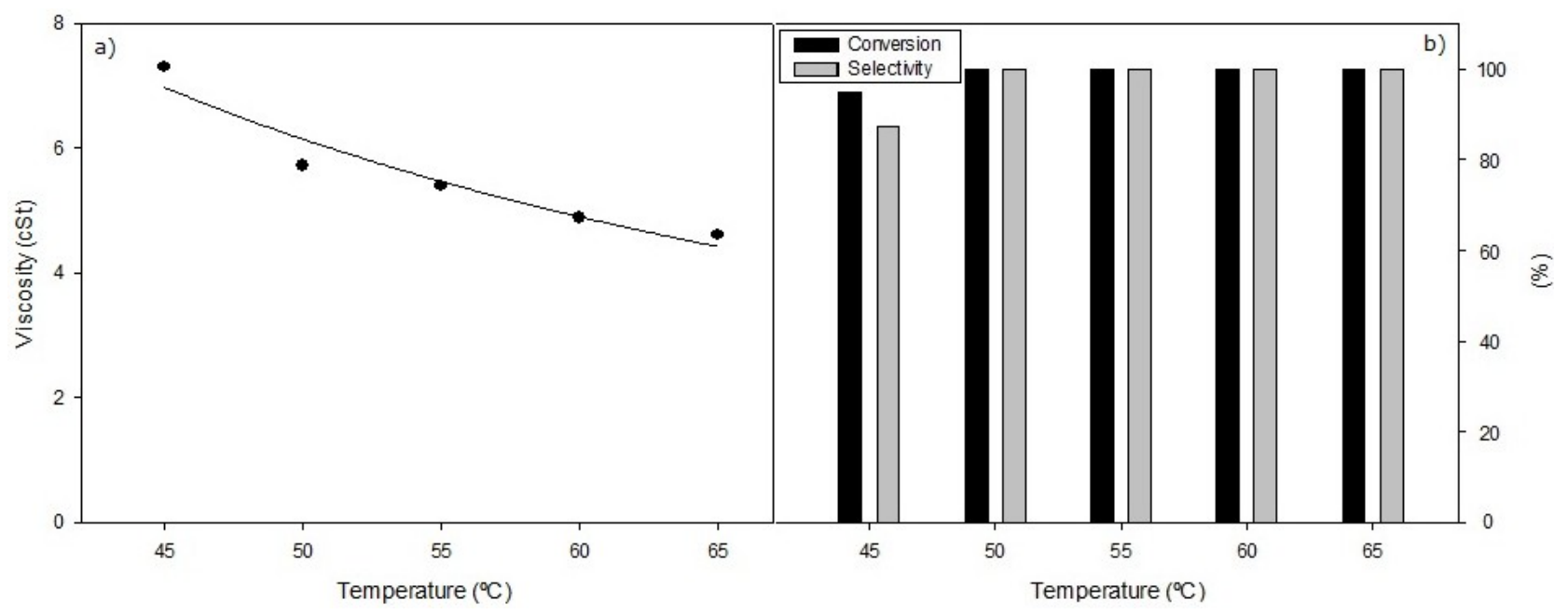

Figure 5. Arrhenius plot ( $\operatorname{Ln} k$ vs. 1/T) obtained from the evolution of $\operatorname{Ln} k$ values with temperature, where $k=$ viscosity $^{-1}$; operating under standard conditions, with $12 \mathrm{~mL}$ of oil, $2.43 \mathrm{~mL}$ of methanol, $0.8 \mathrm{~g}$ of catalyst weight, $60 \mathrm{~min}$ reaction time and different reaction temperatures in the interval $25-65{ }^{\circ} \mathrm{C}$.

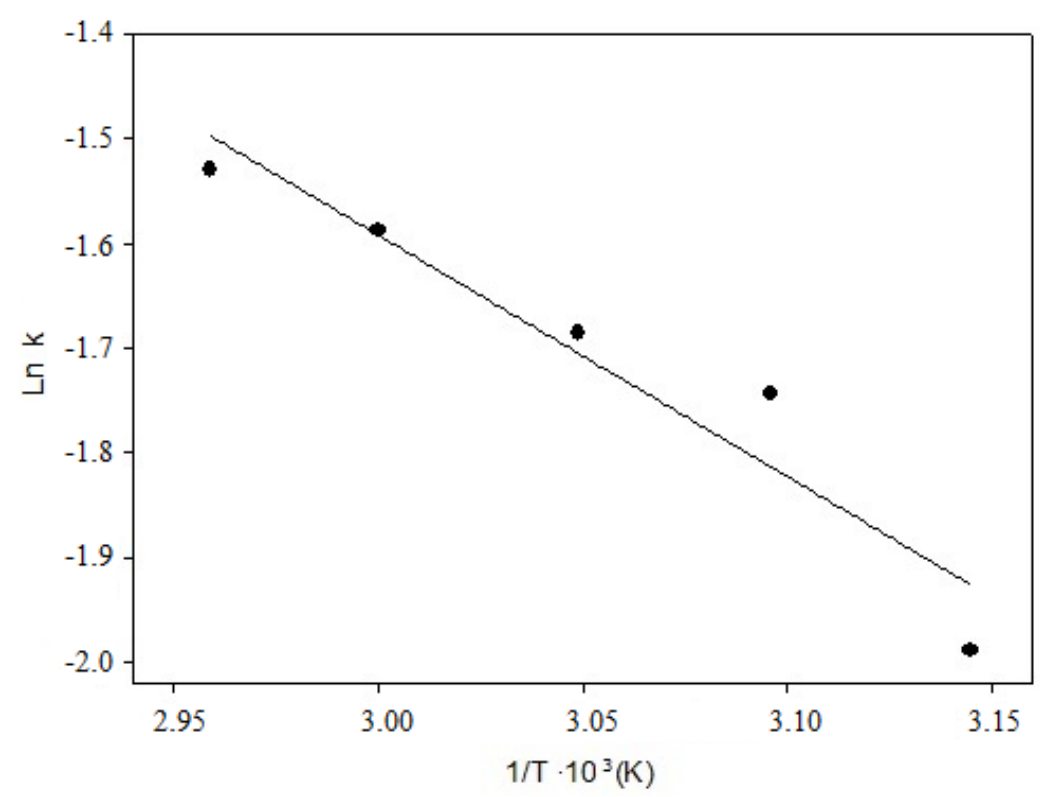

Here we have that $A$ is the Arrhenius pre exponential factor and $E a$ is the activation energy of the reaction. This equation is linear with respect to $1 / T$. If $k$ is determined for varying temperatures, the plot of Lnk vs. $1 / T$ should produce a straight line of slope $-E a / R$. The inverse of kinematic viscosity is used because of this parameter inversely decreases with the progress of the reaction. In this way it is obtained that $\operatorname{Ln} A=5.37$, where $A$ is expressed in $\mathrm{cSt}^{-1}$. Activation energy value $E a=1.16 \mathrm{Kcal} / \mathrm{mol}$ is a relative low value that indicates a low influence of temperature on the reaction rate. Thus, it manifests the higher catalytic activity of the $\mathrm{KF} / \mathrm{Al}_{2} \mathrm{O}_{3}$ catalyst. 
It is also important to note how the Selectivity, the Conversion and the inverse of the kinematic viscosity follow a parallel evolution among them, so that is perfectly demonstrated that with the transformation of TG into DG and this in MG, a gradual reduction in the values of kinematic viscosity is obtained, that is, the viscosity decreases more as the concentration of TG and DG is more reduced. The MG concentration does not appear to affect the viscosity of the mixture in a similar measure as those of TG or DG do. Presumably, the influence of these species in the viscosity of reaction mixture will be directly related to the relative values of their respective molecular weights, so that $\mathrm{TG} \approx 3 / 2 \mathrm{DG} \approx 3 \mathrm{MG} \approx 3 \mathrm{FAME}$.

\subsection{Influence of the Repeated Used of the Three Catalysts, on the Process Performance}

Taking into account that a main advantage of heterogeneous catalysts is the possibility of their reuse, the catalytic behaviour of repeated uses of the three different KF/support catalysts was investigated, where as supports $\mathrm{Al}_{2} \mathrm{O}_{3} \mathrm{ZnO}$ and $\mathrm{MgO}$ have been studied. Figures 6-8 show the variation of Conversion, Selectivity and viscosity over the five studied reuses.

To evaluate the reuses of the different catalysts, in the first reaction $12 \mathrm{~mL}$ sunflower oil and $2.43 \mathrm{~mL}$ methanol (corresponding to a $1 / 6 \mathrm{oil} / \mathrm{methanol}$ molar ratio), and $0.8 \mathrm{~g}$ catalyst ( $7 \mathrm{wt} \%$ ) was used, operating at $65{ }^{\circ} \mathrm{C}$ for $60 \mathrm{~min}$. In the next successive reactions the same amounts of sunflower oil and methanol were added after withdrawing the previous reaction products. Thus, after allowing the reaction product to be decanted for one hour, the supernatant liquid is removed with a pipette and the supported KF solid catalyst remains deposited in the bottom of the flask reactor, ready to be used again in the next reaction.

Figure 6. (a) Viscosity values obtained in the successive reuses of heterogeneous selective methanolysis of sunflower oil under standard conditions, with $0.8 \mathrm{~g}$ of $\mathrm{KF} / \mathrm{Al}_{2} \mathrm{O}_{3}, 65{ }^{\circ} \mathrm{C}$, $12 \mathrm{~mL}$ of oil and $2.43 \mathrm{~mL}$ methanol. (b) Conversion and Selectivity values obtained with identical conditions.

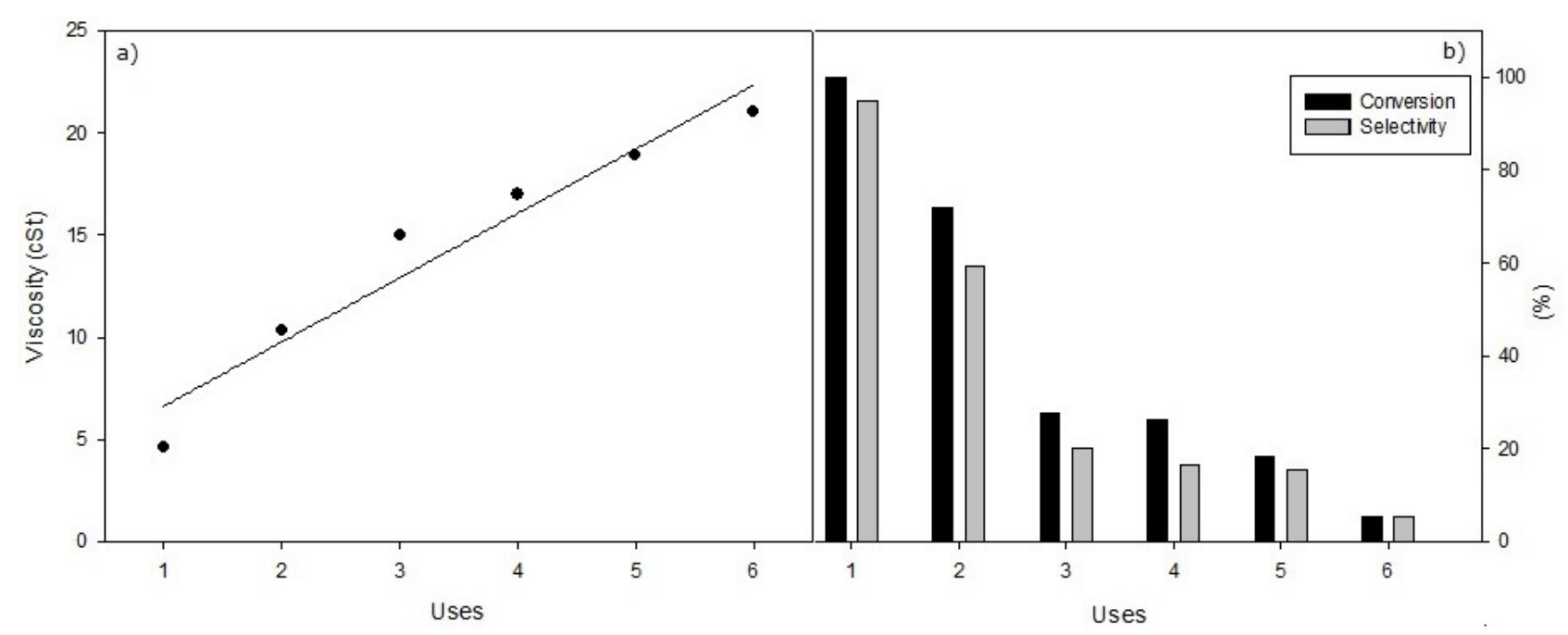


Figure 7. (a) Viscosity values obtained in the successive reuses of heterogeneous selective methanolysis of sunflower oil (viscosity $32.0 \mathrm{cSt}$ ) under standard conditions, with $0.8 \mathrm{~g}$ of $\mathrm{KF} / \mathrm{ZnO}, 65{ }^{\circ} \mathrm{C}, 12 \mathrm{~mL}$ of oil and $2.43 \mathrm{~mL}$ methanol. (b) Conversion and Selectivity values obtained with identical conditions.

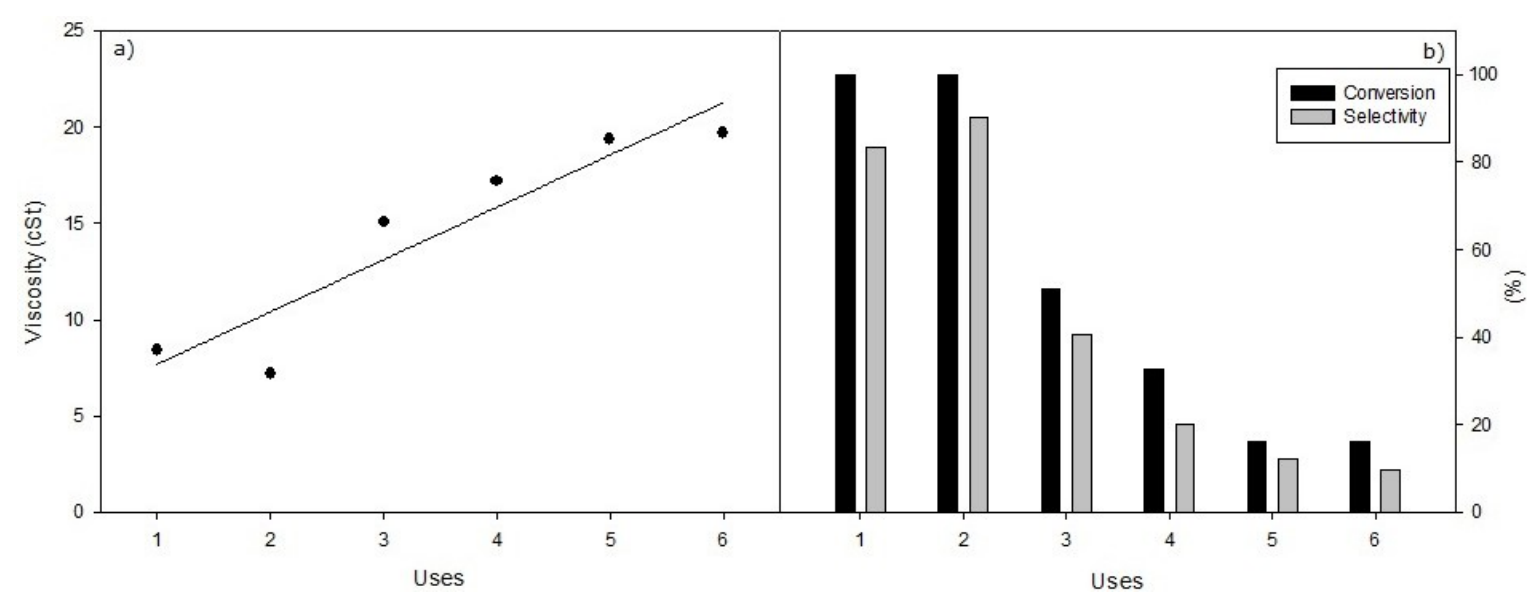

Figure 8. (a) Viscosity values obtained in the successive reuses of heterogeneous selective methanolysis of sunflower oil (viscosity $32.0 \mathrm{cSt}$ ) under standard conditions, with $0.8 \mathrm{~g}$ of $\mathrm{KF} / \mathrm{MgO}, 65{ }^{\circ} \mathrm{C}, 12 \mathrm{~mL}$ of oil and $2.43 \mathrm{~mL}$ methanol. (b) Conversion and Selectivity values obtained with identical conditions.

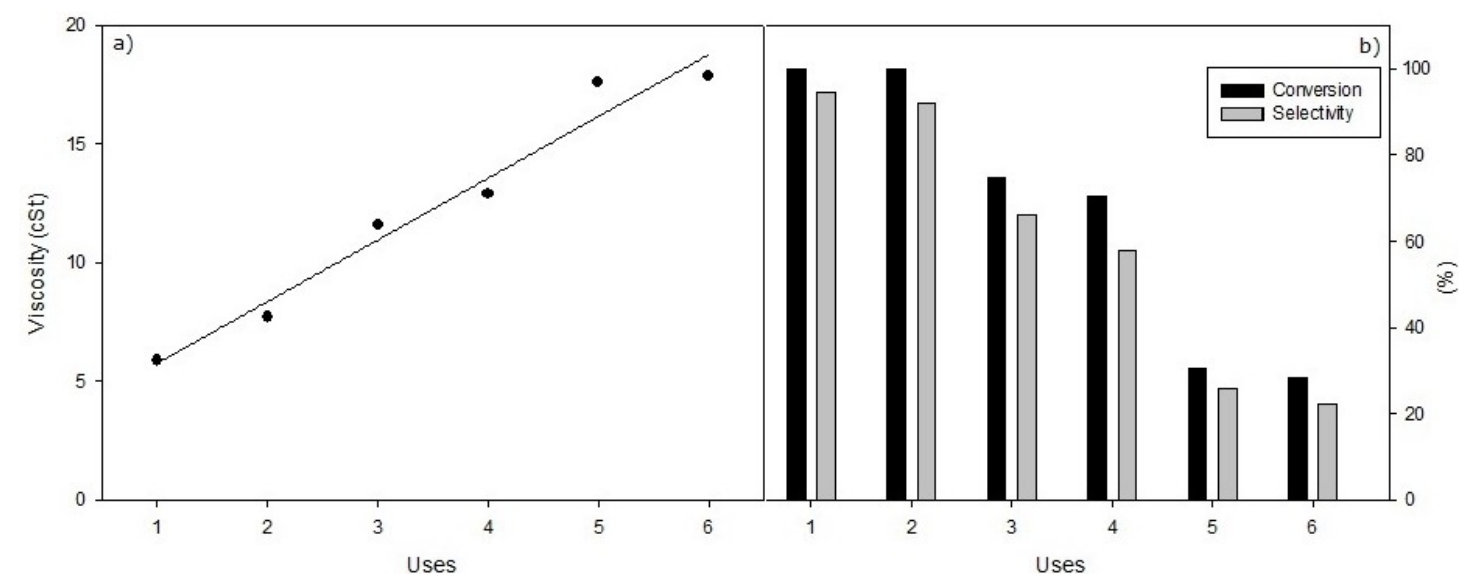

According to the results, with all three supported KF catalysts studied it is obtained that, after the first reaction, Conversion and Selectivity decrease continuously while the kinematic viscosity is increased from 5 to $7 \mathrm{cSt}$ to values close to $20 \mathrm{cSt}$, corresponding to a lowering in the Conversions and Selectivity from $100 \%$ to values lower than $10 \%$. In this respect, $\mathrm{KF} / \mathrm{Al}_{2} \mathrm{O}_{3}$ exhibits the worst catalytic behaviour respect to reuse capability, despite of the fact of being the best heterogeneous KF catalyst studied in the first use. The catalysts $\mathrm{KF} / \mathrm{ZnO}$ and $\mathrm{KF} / \mathrm{MgO}$ allow a second reuse, with the same catalytic behavior seen in the first one, and a softer decline in Conversion and Performance that the $\mathrm{Al}_{2} \mathrm{O}_{3}$ catalyst. However, the $\mathrm{CaO}$ catalyst [27] showed a better performance in regard to the reuse of the heterogeneous catalysts. Catalyst deactivation in no case could be associated to a leaching of the supported KF, according to results obtained after separation of the solid catalysts from the reaction when the reaction was started. These complementary studies, included in the Experimental section, indicate that reaction was always completely interrupted after the separation of supported KF catalyst. 
Thus, no KF was present in the medium reaction. In this way, deactivation ought to be adscribed to some kind of interaction of reaction products or to impurities, like free fatty acids presents in very little amounts in the sunflower oil.

\section{Experimental Section}

\subsection{Materials}

Sunflower oil with a kinematic viscosity of $32 \mathrm{cSt}$ was obtained commercially. Chromatographically pure ethyl esters of palmitic acid, stearic acid, oleic acid, linoleic acid and linolenic acid were commercially obtained from Accustandard (New Haven, CT, USA), and the hexadecane (cetane) from Sigma-Aldrich (St. Louis, MO, USA). The catalysts and the methanol were obtained commercially from Panreac (New Delhi, India) and were of a purity $>99 \%$.

\subsection{Synthesis of Catalysts: Supported KF}

To synthesise of $10 \% \mathrm{KF}$ systems supported on three different inorganic solids $\left(\mathrm{Al}_{2} \mathrm{O}_{3}, \mathrm{ZnO}\right.$ and $\mathrm{MgO})$ an "incipient wetness" impregnation method described previously has been used with a solution of KF (Panreac P.A.), in methanol-water [28]. Thus, support (9 g) and a solution of KF (1 g) mixed in methanol $(5 \mathrm{~mL})$ and water $(2 \mathrm{~mL})$ were mixed with continuous stirring in a rotary evaporator for one hour. Then the solvent was removed by evaporation to dryness. The solid is heated in an oven at $150{ }^{\circ} \mathrm{C}$ for $24 \mathrm{~h}$ to remove solvent residues before use.

\subsection{Alcoholysis Reactions}

The transesterification reaction of food-grade sunflower oil was carried out in a stirred batch reactor, consisting of a $25 \mathrm{~mL}$ volume round bottom flask, which was placed in a thermostatic bath. The reactor, with controlled temperature and stirring speed, is equipped with a reflux condenser to avoid methanol losses. The stirring speed was set at $700 \mathrm{rpm}$ to prevent mass transfer limitations. Sunflower oil, methanol and the activated solid were introduced into the reactor, trying to avoid as much as possible contact between the catalyst and the room atmosphere. After the temperature is raised to the desired value, the reaction starts with the agitation of reactants and catalyst in the reactor. The reaction mixture comprises sunflower oil $(9.4 \mathrm{~g}, 12 \mathrm{~mL}, 0.01 \mathrm{~mol})$, a variable oil/alcohol molar ratio $(1 / 2-1 / 12)$, temperatures in the $30-65{ }^{\circ} \mathrm{C}$ range and different catalyst amounts in the $0.2-1.0 \mathrm{~g}$ range.

In order to exclude the possibility of leaching of KF into the reaction product, some experiments were conducted by measuring the activity of filtrate after $50 \%$ conversion, to prove that the reaction does not go to completion after the supported KF solid catalyst is removed from the reaction medium.

\subsection{Analytical Methods}

Reaction products were monitored at $450{ }^{\circ} \mathrm{C}$ with splitless injection at $350{ }^{\circ} \mathrm{C}$ by capillary column gas chromatography, using a Varian 430-GC gas chromatograph (Varian Medical Systems, Inc., Palo Alto, CA, USA), equipped with a FID (Flame Ionization Detector) and connected to a HT5 capillary column $(25 \mathrm{~m} \times 0.32 \mathrm{~mm} \mathrm{ID} \times 0.1 \mu \mathrm{m})$, SGE, Supelco, (Bellefonte, PA, USA). As carrier gas helium is used, with 
a flow of $1.5 \mathrm{~mL} / \mathrm{min}$. A heating ramp from 50 to $200{ }^{\circ} \mathrm{C}$ at a rate of $7{ }^{\circ} \mathrm{C} / \mathrm{min}$ has been applied, followed by another ramp from 200 to $360^{\circ} \mathrm{C}$ at a rate of $15{ }^{\circ} \mathrm{C} / \mathrm{min}$, maintaining the oven temperature at $360{ }^{\circ} \mathrm{C}$ for 10 min using $n$-hexadecane (cetane) as internal standard to quantify the content of methyl esters and glycerides (-mono, di and triglycerides) with the help of some commercial standard fatty acid esters, respectively. This method allows us to obtain a complete analysis of the sample in a single injection and in a time no longer than $65 \mathrm{~min}$, which simplifies the process and increases the speed of analysis [19-24].

Considering that sunflower oil is constituted by a mixture of fatty acids in variable proportion (mainly linoleic, oleic and stearic acids), reactions results are expressed as the relative amounts of the corresponding FAME, MG and DG, that are integrated in the chromatogram. By difference and respect to the internal standard (cetane), the amount of TG which has not reacted is calculated. The Conversion includes the total amount of triglyceride transformed (FAME $+\mathrm{MG}+\mathrm{DG}$ ) in the methanolysis process and Selectivity makes reference to the relative amount of FAME + MG obtained, which exhibit retention times $(\mathrm{RT}<25)$ similar to conventional diesel fuel $[20,21,27]$.

\subsection{Viscosity Measurements}

Viscosities were determined in an Oswald Proton Cannon-Fenske Routine Viscometer 33200, size 150 capillary viscometer (Sigma-Aldrich). This is based on determining the time needed for a given volume of fluid to pass between two points marked on the instrument. It correlates to the movement restriction suffered by the liquid flow, as a result of its molecules' internal friction, depending on their viscosity. From the flow time, $t$, in seconds, the kinematic viscosity $\left(\mathrm{mm}^{2} / \mathrm{s}\right.$ or centistokes, cSt) can be obtained from the equation: $C \times t=$ viscosity, where $C$ is the constant calibration of the measuring system in $\mathrm{mm}^{2} / \mathrm{s} \times \mathrm{s}$, which is given by the manufacturer $\left(0.040350 \mathrm{~mm}^{2} \cdot \mathrm{s}^{-1}\right.$, at $\left.40{ }^{\circ} \mathrm{C}\right)$ and $\mathrm{t}$ the flow time in seconds [19-24].

The sample, previously centrifuged at $3500 \mathrm{rpm}$ for $10 \mathrm{~min}$, is immersed in a thermostatic bath at $40{ }^{\circ} \mathrm{C}$ for $15 \mathrm{~min}$, making sure that the temperature is stable. Then, the sample is introduced into the viscometer and this, in turn, in the water bath, making sure that it is in rigorously positioned vertically, with the bottom end at a minimum distance of $2 \mathrm{~cm}$ from the floor of the bath.

\section{Conclusions}

In order to improve a new enzymatic methodology developed to obtain a second generation biodiesel that integrates glycerol as monoglyceride [19-24], partial transesterification reactions were achieved through the kinetic control of the chemical reaction. In this respect, supported KF catalysts were evaluated in this study as an inexpensive selective heterogeneous catalyst in the partial methanolysis of sunflower oil to produce an optimal mix with two FAME molecules and one MG molecule for every TG molecule. This biofuel, named Ecodiesel, is applicable to diesel engines because it exhibits similar properties to conventional biodiesel and does not produce glycerol as a by-product. Thus, according to the results the fact that in no case the slightest amount of glycerol was obtained according the GC analysis of the reaction products highlights the undoubted selective character of the consecutive methanolysis process.

We have therefore shown that with any of the three supported KF catalysts studied, the selected experimental conditions represent a significant optimization of the process to obtain in one step a 
biofuel with kinematic viscosity values around 4.5-8.5 cSt, very similar to conventional biodiesel, without generation of any type of residue, since only one phase is obtained, containing FAME, MG, and some little amount of diacylglycerol (DG) as well as the non-reacted methanol, unlike what happens when a larger amount of methanol is used, where two phases are produced. In such case, a conventional transesterification process is developed [38] and variable amounts of glycerol are collected in the lower methanolic phase when a 12/1 molar methanol to oil ratio is used.

On the other hand, some studies [39-42] have proven that blends of diesel fuel and some short chain alcohols, like methanol, with biodiesel produced some less maximum power output than regular diesel. Besides, no significant difference in the emissions of $\mathrm{CO}_{2}, \mathrm{CO}$, and $\mathrm{NO} x$ between regular diesel and biodiesel, methanol and diesel blends was observed. However, the use of these blends resulted in some reduction of particulate matter. Consequently, such blends can be used in a diesel engine without any modification, taking into account the limited changes obtained respect to the use of pure diesel.

On the other hand, the use of conventional biodiesel as a diesel fuel extender and lubricity improver is rapidly increasing. While most of the properties of biodiesel are comparable to those of petroleum-based diesel fuel, improvement of its low temperature flow characteristic still remains one of the major challenges when using biodiesel as an alternative fuel for diesel engines. However, a considerable reduction in pour point has been noticed by using some alcohol as cold flow improver [41]. In this respect, Ecodiesel will display some higher cloud points and pour points than conventional biodiesel; however the presence of methanol as a surplus of the methanolysis reaction will compensate the low temperature flow characteristics. Besides, several additives may be used to maintain the basic chemical functions to improve ignition and combustion efficiency and to stabilize such fuel mixtures [42]. Thus, it can be used directly after its production because it is obtained in only one phase and no purification step of residual glycerol or methanol is necessary.

Furthermore, to obtain this biofuel it is not necessary operate at high pressures and temperatures. On the contrary, this new biodiesel is obtained under mild reaction conditions, at atmospheric pressure, 6/1 methanol to oil molar ratio, $7 \mathrm{wt} \%$ catalyst respect to oil, $65{ }^{\circ} \mathrm{C}$ reaction temperature and $60 \mathrm{~min}$ reaction time. Besides, a comparatively higher yield is obtained respect to the conventional biodiesel reaction, because no glycerol is generated as byproduct.

Finally, although it was seen that after the second reuse a decrease in the catalytic activity occurs, this low cost heterogeneous process may be comparatively more profitable than the enzymatic process, due to the higher cost of commercial lipases.

\section{Acknowledgments}

Grants from the Spanish Ministry of Economy and Competitiveness (Project ENE 2011-27017), Spanish Ministry of Education and Science (Projects CTQ2010-18126 and CTQ2011-28954-C02-02), FEDER funds and Junta de Andalucía FQM 0191, PO8-RMN-03515 and P11-TEP-7723 are gratefully acknowledged by the authors.

\section{Author Contributions}

All co-authors have made substantive intellectual contributions to this study, making substantial contributions to conception and design of it, as well as to the acquisition, analysis and interpretation of 
data. All of them have been also involved in drafting and revising the manuscript, so that everyone has given final approval of the current version to be published in Energies Journal.

\section{Conflicts of Interest}

The authors declare no conflict of interest.

\section{References}

1. Atadashi, I.M.; Aroua, M.K.; Abdul-Aziz, A. High quality biodiesel and its diesel engine application: A review. Renew. Sustain. Energy Rev. 2010, 14, 1999-2008.

2. Dhar, A.; Kevin, R.; Agarwal, A.K. Production of biodiesel from high-FFA neem oil and its performance, emission and combustion characterization in a single cylinder DICI engine. Fuel Process. Technol. 2012, 97, 118-129.

3. Luque, R.; Herrero, L.; Campelo, J.M.; Clark, J.A.; Hidalgo, J.M.; Luna, D.; Marinas, J.M.; Romero, A.A. Biofuels: A technological perspective. Energy Environ. Sci. 2008, 1, 513-596.

4. Luna, D.; Berbel, J.; Hidalgo, J.M. Nous tipus de biodiesel. Rev. Soc. Catalana Quím. 2009, 9 , 23-32. (In Catalan)

5. Fukuda, H.; Kondo, A.; Noda, H. Biodiesel fuel production by transesterification of oils. J. Biosci. Bioeng. 2001, 92, 405-416.

6. Felizardo, P.; Machado, J.; Vergueiro, D.; Correia, M.J.N.; Gomes, J.P.; Bordado, J.M. Study on the glycerolysis reaction of high free fatty acid oils for use as biodiesel feedstock. Fuel Proc. Technol. 2011, 92, 1225-1229.

7. Oha, P.P.; Lau, H.L.N.; Chen, J.; Chong, M.F.; Choo, Y.M. A review on conventional technologies and emerging process intensification (PI) methods for biodiesel production. Renew. Sustain. Energy Rev. 2012, 16, 5131-5145.

8. Jaichandar, S.; Annamalai, K. The status of biodiesel as an alternative fuel for diesel engine-An overview. J. Sustain. Energy Environ. 2011, 2, 71-75.

9. Yusuf, N.N.A.N.; Kamarudin, S.K.; Yaakub, Z. Overview on the current trends in biodiesel production. Energy Convers. Manag. 2011, 52, 2741-2751.

10. Corma, A.; Huber, G.W.; Sauvanaud, L.; O’Connor, P. Processing biomass-derived oxygenates in the oil refinery: Catalytic cracking (FCC) reaction pathways and role of catalyst. J. Catal. 2007, 247, 307-327.

11. Behr, A.; Eilting, J.; Leschinski, J.; Lindner, F. Improved utilization of renewable resources: New important derivatives of glycerol. Green Chem. 2008, 10, 13-30.

12. Luna, D.; Calero, J.; Sancho, E.D.; Luna, C.; Posadillo, A.; Bautista, F.M.; Romero, A.A.; Berbel, J.; Verdugo, C. Technological challenges for the production of biodiesel in arid lands. J. Arid Environ. 2014, 102, 127-138.

13. Fabbri, D.; Bevoni, V.; Notari, M.; Rivetti, F. Properties of a potential biofuel obtained from soybean oil by transmethylation with dimethyl carbonate. Fuel 2007, 86, 690-697.

14. Su, E.Z.; Zhang, M.J.; Zhang, J.G.; Gao, J.F.; Wei, D.Z. Lipase-catalyzed irreversible transesterification of vegetable oils for fatty acid methyl esters production with dimethyl carbonate as the acyl acceptor. Biochem. Eng. J. 2007, 36, 167-173. 
15. Notari, M.; Rivetti, F. Use of a Mixture of Esters of Fatty Acids as Fuel or Solvent. WO/2004/052874, 24 June 2004.

16. Kijeński, J.; Lipkowski, A.; Walisiewicz-Niedbalska, W.; Gwardiak, H.; Różyczki, K.; Pawlak, I. A Biofuel for Compression-Ignition Engines and a Method for Preparing the Biofuel. EP1580255 A1, 28 September 2004.

17. Xu, Y.; Du, W.; Liu, D. Study on the kinetics of enzymatic interesterification of triglycerides for biodiesel production with methyl acetate as the acyl acceptor. J. Mol. Catal. B Enzym. 2005, 32, 241-245.

18. Modi, M.K.; Reddy, J.R.C.; Rao, B.V.S.K.; Prasad, R.B.N. Lipase-mediated conversion of vegetable oils into biodiesel using ethyl acetate as acyl acceptor. Bioresour. Technol. 2007, 98, 1260-1264.

19. Verdugo, C.; Luna, D.; Posadillo, A.; Sancho, E.D.; Rodríguez, S.; Bautista, F.; Luque, R.; Marinas, J.M.; Romero, A.A. Production of a new second generation biodiesel with a low cost lipase derived from Thermomyces lanuginosus: Optimization by response surface methodology. Catal. Today 2011, 167, 107-112.

20. Luna, D.; Posadillo, A.; Caballero, V.; Verdugo, C.; Bautista, F.M.; Romero, A.A.; Sancho, E.D.; Luna, C.; Calero, J. New biofuel integrating glycerol into its composition through the use of covalent immobilized pig pancreatic lipase. Int. J. Mol. Sci. 2012, 13, 10091-10112.

21. Luna, C.; Sancho, E.D.; Luna, D.; Caballero, V.; Calero, J.; Posadillo, A.; Verdugo, C.; Bautista, F.M.; Romero, A.A. Biofuel that Keeps Glycerol as Monoglyceride by 1,3-Selective Ethanolysis with Pig Pancreatic Lipase Covalently Immobilized on $\mathrm{AlPO}_{4}$ Support. Energies 2013, 6, 3879-3900.

22. Luna, D.; Bautista, F.M.; Caballero, V.; Campelo, J.M.; Marinas, J.M.; Romero, A.A. Method for the Biodiesel Production by Using Pig Pancreatic Lipase as Enzymatic Catalyst. WO/2008/009772, 24 January 2008.

23. Caballero, V.; Bautista, F.M.; Campelo, J.M.; Luna, D.; Marinas, J.M.; Romero, A.A.; Hidalgo, J.M.; Luque, R.; Macario, A.; Giordano, G. Sustainable preparation of a novel glycerol-free biofuel by using pig pancreatic lipase: Partial 1,3-regiospecific alcoholysis of sunflower oil. Process Biochem. 2009, 44, 334-342.

24. Verdugo, C.; Luque, R.; Luna, D.; Hidalgo, J.M.; Posadillo, A.; Sancho, E.D.; Rodriguez, S.; Ferreira-Dias, S.; Bautista, F.; Romero, A.A. A comprehensive study of reaction parameters in the enzymatic production of novel biofuels integrating glycerol into their composition. Bioresour. Technol. 2010, 101, 6657-6662.

25. Hu, J.; Du, Z.; Li, C.; Min, E. Study on the lubrication properties of biodiesel as fuel lubricity enhancers. Fuel 2005, 84, 1601-1606.

26. Knothe, G.; Steidley, K.R. Kinematic viscosity of biodiesel components (fatty acid alkyl esters) and related compounds at low temperatures. Fuel 2007, 86, 2560-2567.

27. Calero, J.; Luna, D.; Sancho, E.D.; Luna, C.; Bautista, F.M.; Romero, A.A.; Posadillo, A.; Verdugo, C. Development of a new biodiesel that integrates glycerol, by using $\mathrm{CaO}$ as heterogeneous catalyst, in the partial methanolysis of sunflower oil. Fuel 2014, 122, 94-102. 
28. Bautista, F.M.; Campelo, J.M.; García, A.; Luna, D.; Marinas, J.M.; Romero, A.A. Study on dry-media microwave azalactone synthesis on different supported KF cayalysis: Influence of textural and acid-base properties of supports. J. Chem. Soc. Perkin Trans. 2002, 2, 227-234.

29. Xie, W.; Huang, X. Synthesis of Biodiesel soybean oil using heterogeneous $\mathrm{KF} / \mathrm{ZnO}$ catalyst. Catal. Lett. 2006, 107, 53-59.

30. Xu, B.; Xiao, G.; Cui, L.; Wei, R.; Gao, L. Transesterification of Palm Oil with Methanol to Biodiesel over a $\mathrm{KF} / \mathrm{Al}_{2} \mathrm{O}_{3}$ Heterogeneous Base Catalyst. Energy Fuels 2007, 21, 3109-3112.

31. Sun, H.; Hu, K.; Lou, H.; Zheng, X. Biodiesel Production from Transesterification of Rapeseed Oil Using $\mathrm{KF} / \mathrm{Eu}_{2} \mathrm{O}_{3}$ as a Catalyst. Energy Fuels 2008, 22, 2756-2760.

32. Boz, N.; Degirmenbasi, N.; Kalyon, D.M. Conversion of biomass to fuel: Transesterification of vegetable oil to biodiesel using $\mathrm{KF}$ loaded nano-g- $\mathrm{Al}_{2} \mathrm{O}_{3}$ as catalyst. Appl. Catal. B Environ. 2009, 89, 590-596.

33. Gao, L.; Xu, B.; Xiao, G.; Lv, J. Transesterification of Palm Oil with Methanol to Biodiesel over a KF/Hydrotalcite Solid Catalyst. Energy Fuels 2008, 22, 3531-3535.

34. Liu, X.; He, H.; Wang, Y.; Zhu, S.; Piao, X. Transesterification of soybean oil to biodiesel using $\mathrm{CaO}$ as a solid base catalyst. Fuel 2008, 87, 216-221.

35. Fan, M.; Zhang, P.; Ma, Q. Enhancement of biodiesel synthesis from soybean oil by potassium fluoride modification of a calcium magnesium oxides catalyst. Bioresour. Technol. 2012, 104, $447-450$.

36. Wan, T.; Yu, P.; Gong, S.; Li, Q.; Luo, Y. Application of KF/MgO as a heterogeneous catalyst in the production of biodiesel from rapeseed oil. Korean J. Chem. Eng. 2008, 25, 998-1003.

37. Verziu, M.; Florea, M.; Simon, S.; Simon, V.; Filip, P.; Parvulescu, V.I.; Hardacre, C. Transesterification of vegetable oils on basic large mesoporous alumina supported alkaline fluorides-Evidences of the nature of the active site and catalytic performances. J. Catal. 2009, 263, 56-66.

38. Dias, A.P.S.; Puna, J.; Correia, M.J.N.; Isabel, N.; Gomes, J.; Bordado, J. Effect of the oil acidity on the methanolysis performances of lime catalyst biodiesel from waste frying oils (WFO). Fuel Proc. Technol. 2013, 116, 94-100.

39. Cheenkachorn, K.; Fungtammasan, B. Biodiesel as an additive for diesohol. Int. J. Green Energy 2009, 6, 57-72.

40. Jaganjac, M.; Prah, I.O.; Cipak, A.; Cindric, M.; Mrakovcic, L.; Tatzber, F.; Ilincic, P.; Rukavina, V.; Spehar, B.; Vukovic, J.P.; et al. Effects of bioreactive acrolein from automotive exhaust gases on human cells in vitro. Environ. Toxicol. 2011, 27, 644-652.

41. Bhale, P.V.; Deshpande, N.V.; Thombre, S.B. Improving the low temperature properties of biodiesel fuel. Renew. Energy 2009, 34, 794-800.

42. Ribeiro, N.M.; Pinto, A.C.; Quintella, C.M.; Rocha, G.O.; Teixeira, L.S.G.; Guarieiro, L.L.N.; Rangel, M.C.; Veloso, M.C.C.; Rezende, M.J.C.; Cruz, R.S.; et al. The role of additives for diesel and diesel blended (ethanol or biodiesel) fuels: A review. Energy Fuels 2007, 21, 2433-2445.

(C) 2014 by the authors; licensee MDPI, Basel, Switzerland. This article is an open access article distributed under the terms and conditions of the Creative Commons Attribution license (http://creativecommons.org/licenses/by/3.0/). 